\title{
Glinicopathological Studies on the Relationship between Cholelithiasis and Chronic Pancreatitis
}

\author{
Toshio Sato, Yoichi Saitoh, Noboru Noto, Seiki Matsuno \\ and Koki Tokutake
}

Department of Surgery, Tohoku University School of Medicine, Sendai

\begin{abstract}
Sato, T., Saitoh, Y., Noto, N., Matsuno, S. and Tokdtake, K. Clinicopathological Studies on the Relationship between Cholelithiasis and Chronic Pancreatitis. Tohoku J. exp. Med., 1974, 113 (2), 97-111-In order to investigate the relationship between cholelithiasis and chronic pancreatitis, biopsy of the pancreas was performed, at laparotomy in $15 \mathrm{l}$ cases with cholelithiasis, and the pancreatic exocrine function test using secretin was applied in 119 out of them. Thirty-one cases with gastric lesion were served as controls. The disturbance of the pancreatic exocrine function was demonstrated in $30(25 \%)$ of the 119 cases; mildly disturbed in 25, moderately in 4, and markedly in one. Of a total of 30 cases with disturbed pancreatic exocrine function, there were 10 cases with decreased volume of the duodenal aspirate, 17 with decreased maximum bicarbonate concentration and 9 with decreased output of amylase. Thus, cases with reduced maximum bicarbonate concentration were most frequently observed. In the majority of the cases with bacteria in bile, with common bile duct dilatation and with hypercholesterolemia, the disturbance of the pancreatic exocrine function of moderate and marked degree was observed. A significant correlation was indicated between the histology of the pancreas and the result of the secretin test in the cases with moderately and markedly disturbed exocrine function. However, no significant difference was demonstrated between the controls and the group of cholelithiasis in morphological features. Only 5 eases $(3 \%)$ of 151 cases with cholelithiasis were regarded as chronic pancreatitis.

chronic pancreatitis; cholecystopancreatitis; gallstone pancreatitis; chronic pancreopathy; secretin test
\end{abstract}

The relationship between cholelithiasis and pancreatitis has been attended since many years ago. Mallet-Guy and Beaujeu (1950) published a detailed report thereon with a title of cholecystopancreatitis, while Howard and Jordan (1960) did it under a name of gallstone pancreatitis, and Hess (1965) under a term of chronic pancreopathy. As pointed out by White (1966), however, considerable discrepancy has been noted among many authors in various countries on the relationship between cholelithiasis and pancreatitis. In order to clarify the relationship between cholelithiasis and pancreatitis, we studied on the exocrine function and histology of the pancreas in patients with cholelithiasis.

Received for publication, March 19, 1974. 


\section{Subjects and Methods}

All the subjects who underwent laparotomy in our clinic under the diagnosis of cholelithiasis from February 1970 to September 1972 were examined. They included 69 males and 82 females, 151 in total; two cases younger than 19 years, 11 in the third decade, 20 in the fourth, 41 in the fifth, 43 in the sixth, 25 in the seventh, and nine in the eighth. The gallstones were located in the gallbladder in 113 patients, in the bile duct in 14, and in both gallbladder and bile duct in 24. As a nature of gallstones, cholesterol stones were seen in 115 patients, calcium bilirubinate stones in 34, and others in two. If those whose bile ducts were less than $8 \mathrm{~mm}$ in diameter in the preoperative and/or intraoperative cholangiography are called non-dilated ones, and those whose counterparts were more than $8 \mathrm{~mm}$ are called dilated ones, 62 had dilated bile duct, whereas 87 had non-dilated one. In addition, bile was collected from gallbladder before cholecystectomy for subsequent culture in order to detect bacteria in 119 patients, of whom 47 were positive with bacteria, while 72 were negative. Bacteria in the positive cases could be classified into $\mathrm{E}$. coli in 41 patients, Klebsiella in three, and Proteus in three. The patients could be classified, in terms of total cholesterol content in serum, into 27 with higher values and two with lower values, while the remaining 86 were within the range of normal values. The chief complaints of the patients with cholelithiasis were mostly abdominal pains. The duration from the onset to the initial visit to our clinic was 40 years at the longest and two weeks at the shortest, including 63 within one year, 45 within one to five years, 20 within five to 10 years and 17 within more than 10 years, while six complained of no pain.

The secretin test was applied to the exocrine function of the pancreas. The duodenal aspirate was examined in terms of volume, maximum bicarbonate concentration, and total amylase output. The bicarbonate concentration was measured with Van Slyke's method, while amylase was determined with Somogyi's method and Caraway's method. The lower limit of normal values of the volume of duodenal aspirate, maximum bicarbonate concentration, and total amylase output were $1.8 \mathrm{ml} / \mathrm{kg}, 80 \mathrm{mEq} / \mathrm{liter}$, and $650 \mathrm{u} / \mathrm{kg}$, respectively. The result was classified into mild disturbance when only one of the three values was low, moderate disturbance when two of the three values were low, and marked disturbance when all of the three values were low. Biopsy of pancreas was done at the lower edge of the head of the pancreas, whereby pancreatic parenchyma of soybean size was excised. The specimen thus excised was immediately immersed into Bouin's solution for fixation for 12 to 24 hours, followed by dehydration and defatting. The resulting substance was processed into parafiin-embedded sections and then stained with H.E. and Elastica Masson staining.

\section{RESUlts}

\section{Results of the pancreatic exocrine function test}

Of 119 patients who underwent the secretin test, $89(74.8 \%)$ were found normal and $25(21.0 \%)$ were found slightly disturbed, while four $(3.4 \%)$ were moderately disturbed and one $(0.8 \%)$ was markedly disturbed. Of the patients with slight disturbance, eight patients had reduced volume of duodenal aspirate and 12 had reduced maximum bicarbonate concentration, while five had reduced total amylase output. Of the moderately disturbed patients, one had both reduced maximum bicarbonate concentration and reduced volume of duodenal aspirate, while three had both reduced maximum bicarbonate concentration and reduced total amylase output. Viewed from the factors of disturbance, 36 factors of disturbance could be classified into 10 patients $(27.8 \%)$ with reduced volume of duodenal aspirate, 17 $(47.2 \%)$ with reduced maximum bicarbonate concentration, and nine $(25.0 \%)$ with reduced total amylase output. If viewed from the patients with disturbance, the 
total 30 patients were classified into $10(33.3 \%)$ with reduced volume of duodenal aspirate, $17(56.7 \%)$ with reduced maximum bicarbonate concentration and nine $(30.0 \%)$ with reduced total amylase output. Thus, cases with reduced maximum bicarbonate concentration were most frequently observed.

Relationship between the location and type of gallstones and the results of the secretin test: Table 1 indicates the results of the secretin test in terms of location of gallstone, in which abnormal pancreatic exocrine function was seen in $21(22.6 \%)$ of 93 patients with gallstones in the gallbladder, in seven (43.8\%) of 16 with stones in both gallbladder and bile duct, and in two $(20.0 \%)$ of 10 patients with stone in the bile duct alone. Of these, $18(19.4 \%)$ with stones in the gallbladder, five $(31.3 \%)$ with stones in both gallbladder and bile duct, and two $(20 \%)$ with stone in the bile duct were those with mild disturbance. On the other hand, among the patients with moderate disturbance, three $(3.2 \%)$ were with gallstones in the gallbladder, while another one $(6.3 \%)$ had stones in both gallbladder and bile duct. A patient $(6.3 \%)$ with marked disturbance had stones in the gallbladder and bile duct. Although the group with stones in both gallbladder and bile duct with moderate and marked disturbance was in greater frequency than the other two groups as shown in Table 1, there was no statistically significant difference between the former and the latter.

TABLE 1. Relationship between location of gallstone and results of the secretin test

\begin{tabular}{|c|c|c|c|c|c|}
\hline \multirow[b]{2}{*}{ Location of gallstone } & \multirow[b]{2}{*}{$\begin{array}{l}\text { Number of } \\
\text { patients }\end{array}$} & \multicolumn{4}{|c|}{ Results of secretin test } \\
\hline & & Normal & Mild disturb. & $\begin{array}{l}\text { Moderate } \\
\text { disturb. }\end{array}$ & $\begin{array}{l}\text { Marked } \\
\text { disturb. }\end{array}$ \\
\hline Gallbladder & 93 & $\begin{array}{c}72 \\
(77.4)\end{array}$ & $\begin{array}{c}18 \\
(19.4)\end{array}$ & $\begin{array}{c}3 \\
(3.2)\end{array}$ & \\
\hline $\begin{array}{l}\text { Gallbladder and bile } \\
\text { duct }\end{array}$ & 16 & $\begin{array}{c}9 \\
(56.3)\end{array}$ & $\left(\begin{array}{c}5 \\
(31.3)\end{array}\right.$ & $\begin{array}{c}1 \\
(6.3)\end{array}$ & $\begin{array}{c}1 \\
(6.3)\end{array}$ \\
\hline Bile duct & 10 & $\begin{array}{c}8 \\
(80.0)\end{array}$ & $\begin{array}{c}2 \\
(20.0)\end{array}$ & & \\
\hline Total & 119 & $\begin{array}{c}89 \\
(74.8)\end{array}$ & $\begin{array}{c}25 \\
(21.0)\end{array}$ & $\left(\begin{array}{c}4 \\
(3.4)\end{array}\right.$ & $\begin{array}{c}1 \\
(0.8)\end{array}$ \\
\hline
\end{tabular}

Percentages are shown in parentheses.

Table 2 shows the relationship between the type of gallstone and the results of the secretin test. In the group with cholesterol stones, $70(72.9 \%)$ were found normal, whereas $22(22.9 \%)$ were with mild disturbance, three $(3.1 \%)$ with moderate disturbance, and one $(1.0 \%)$ with marked disturbance. In the group with calcium bilirubinate stones, $17(81.0 \%)$ were found normal, whereas three $(14.3 \%)$ were with mild disturbance, and one $(4.8 \%)$ had moderate disturbance. In the group with stones of the other type, both two showed normal results in the secretin test. The cases with disturbance of the secretin test were found in $26(27.1 \%)$ 
TABLE 2. Relationship between type of gallstone and results of the secretin test

\begin{tabular}{|c|c|c|c|c|c|}
\hline \multirow[b]{2}{*}{ Type of stone } & \multirow{2}{*}{$\begin{array}{l}\text { Number of } \\
\text { patients }\end{array}$} & \multicolumn{4}{|c|}{ Results of secretin test } \\
\hline & & Normal & Mild disturb. & $\begin{array}{l}\text { Moderate } \\
\text { disturb. }\end{array}$ & $\begin{array}{l}\text { Marked } \\
\text { disturb. }\end{array}$ \\
\hline Cholesterol stone & 96 & $\begin{array}{c}70 \\
(72.9)\end{array}$ & $\begin{array}{c}22 \\
(22.9)\end{array}$ & $\stackrel{3}{(3.1)}$ & $(1.0)$ \\
\hline $\begin{array}{l}\text { Calcium } \\
\text { bilirubinate stone }\end{array}$ & 21 & $\begin{array}{c}17 \\
(81.0)\end{array}$ & $\begin{array}{c}3 \\
(14.3)\end{array}$ & $\begin{array}{c}1 \\
(4.8)\end{array}$ & \\
\hline Others & 2 & $\stackrel{2}{2}(100.0)$ & & & \\
\hline Total & 119 & 89 & 25 & 4 & 1 \\
\hline
\end{tabular}

out of 96 , more in the group with cholesterol stones than the counterparts in the group with calcium bilirubinate stones, which were found in four $(19.0 \%)$ out of 21. However, there was no significant difference between the two groups.

Relationship between the dilatation of bile duct and the results of the secretin test: The disturbance in the secretin test was seen in $12(26.7 \%)$ out of 45 patients with dilatation of bile duct, whereas in the group without dilatation of bile duct, the disturbance was seen in $18(24.7 \%$ ) out of 73 patients (Table 3$)$. In terms of frequency of cases with moderate and marked disturbance in the secretin test, the dilated group showed four $(8.9 \%)$ thereof, whereas the non-dilated group showed only one $(1.4 \%)$. No significant difference was seen between the dilated and the non-dilated groups, but it may be said that the dilated group was prone to have more cases with moderate and marked disturbance in the secretin test than the non-dilated group $(p=0.095)$.

TABLE 3. Relationship between dilatation of bile duct and results of the secretin test

\begin{tabular}{cccccc}
\hline Bile duct & \multirow{2}{*}{$\begin{array}{c}\text { Number of } \\
\text { patients }\end{array}$} & Normal & Mild disturb. & $\begin{array}{c}\text { Moderate } \\
\text { disturb. }\end{array}$ & $\begin{array}{c}\text { Marked } \\
\text { disturb. }\end{array}$ \\
\hline Non-dilated group & 73 & 55 & 17 & 1 & \\
Dilated group & 45 & $(75.3)$ & $(23.3)$ & $(1.4)$ & \\
& & 33 & 8 & 3 & 1 \\
Total & 118 & 88 & 25 & 4 & 1 \\
\hline
\end{tabular}

Relationship between the results of the culture of bacteria in bile and the results of the secretin test: Of all the 92 patients who underwent the secretin test with subsequent culture of bacteria in bile, 31 were positive in bacteria. As showed in the Table 4 , the disturbance in the secretin test was seen in $11(35.5 \%)$ out of 31 in the positive group and $14(23.0 \%)$ out of 61 in the negative group. Particularly, 
TABLE 4. Relationship between results of culture of bacteria in bile and results of secretin test

\begin{tabular}{cccccc}
\hline & Number of & \multicolumn{4}{c}{ Results of secretin test } \\
\cline { 5 - 6 } Bacteria in bile & patients & Normal & Mild disturb. & $\begin{array}{c}\text { Moderate } \\
\text { disturb. }\end{array}$ & $\begin{array}{c}\text { Marked } \\
\text { disturb. }\end{array}$ \\
\hline Negative group & 61 & $\begin{array}{c}47 \\
(77.0)\end{array}$ & $\begin{array}{c}12 \\
19.7\end{array}$ & $\begin{array}{c}1 \\
(1.6)\end{array}$ & $\begin{array}{c}1 \\
(1.6)\end{array}$ \\
Positive group & 31 & $\begin{array}{c}20 \\
(64.5)\end{array}$ & $(29.0)$ & $(6.5)$ & \\
\hline Total & 92 & 67 & 21 & 3 & 1 \\
\hline
\end{tabular}

two $(6.5 \%)$ in the positive culture group had moderate and marked disturbance. No significant difference was seen between the normal and disturbed cases in the secretin test in terms of the results of culture of bacteria in bile. However, if particularly examined on the cases with moderate and marked disturbances in the secretin test, a significant difference was observed between the positive and negative groups of bacteria in bile; more cases with moderate and marked disturbance in the secretin test were seen in the positive group of bacteria in bile than in the negative group $(\mathrm{p}<0.01)$.

Relationship between the duration of symptoms and the results of the secretin test: As shown in Table 5, disturbed cases in the secretin test were seen in $15(29.4 \%)$ out of 51 with duration of symptoms less than one year, eight $(22.9 \%)$ out of 35 with duration of one to five years, three $(18.8 \%)$ out of 16 with duration of five to 10 years, and three $(20.0 \%)$ out of 15 with duration more than 10 years. No significant difference was seen between the duration of symptoms and the results of the secretin test.

TABLE 5. Relationship between duration of symptoms and results of secretin test

\begin{tabular}{|c|c|c|c|c|c|}
\hline \multirow[b]{2}{*}{ Duration of symptoms } & \multirow[b]{2}{*}{$\begin{array}{c}\text { Number of } \\
\text { patients }\end{array}$} & \multicolumn{4}{|c|}{ Results of secretin test } \\
\hline & & Normal & Mild disturb. & $\begin{array}{l}\text { Moderate } \\
\text { disturb. }\end{array}$ & $\begin{array}{l}\text { Marked } \\
\text { disturb. }\end{array}$ \\
\hline-1 year & 51 & $\begin{array}{c}36 \\
(70.6)\end{array}$ & $\begin{array}{c}12 \\
(23.5)\end{array}$ & $\begin{array}{c}2 \\
(3.9)\end{array}$ & $(2.0)$ \\
\hline $1-5$ years & 35 & $\begin{array}{c}27 \\
(77.1)\end{array}$ & $\begin{array}{c}7 \\
(20.0)\end{array}$ & $\begin{array}{c}1 \\
(2.9)\end{array}$ & \\
\hline $5-10$ years & 16 & $\begin{array}{c}13 \\
(81.3)\end{array}$ & $\begin{array}{c}3 \\
(18.8)\end{array}$ & & \\
\hline 10 years - & 15 & $\begin{array}{c}12 \\
(80.0)\end{array}$ & $\left(\begin{array}{c}2 \\
(13.3)\end{array}\right.$ & $\begin{array}{c}1 \\
(6.7)\end{array}$ & \\
\hline (Without pain) & 2 & 1 & 1 & & \\
\hline Total & 119 & 89 & 25 & 4 & 1 \\
\hline
\end{tabular}


Relationship between the total cholesterol content of serum and the results of the secretin test: In 99 patients, both serum cholesterol content determination and the secretin test were performed. The cases with normal content range (125-250 $\mathrm{mg} / 100 \mathrm{ml}$ ) were observed in 75 . Of 22 patients who showed higher serum content, seven $(31.8 \%)$ had disturbance in the secretin test, while out of 75 patients with normal range, $17(22.6 \%)$ showed disturbance in the secretin test, showing no significant difference between each other. However, the patients showing moderate and marked disturbances in the secretin test were seen in three $(13.6 \%)$ out of 22 in the higher serum cholesterol content group and one (1.4\%) out of 75 in the normal group. This indicates significant difference showing that moderate and marked disturbances in the secretin test were more frequent in the patients with higher serum cholesterol content $(p<0.05)$.

TABLE 6. Relationship between total cholesterol content of serum and results of secretin test

\begin{tabular}{|c|c|c|c|c|c|}
\hline \multirow{2}{*}{$\begin{array}{l}\text { Value of total } \\
\text { cholesterol }\end{array}$} & \multirow{2}{*}{$\begin{array}{c}\text { Number of } \\
\text { patients }\end{array}$} & \multicolumn{4}{|c|}{ Results of secretin test } \\
\hline & & Normal & Mild disturb. & $\begin{array}{l}\text { Moderate } \\
\text { disturb. }\end{array}$ & $\begin{array}{l}\text { Marked } \\
\text { disturb. }\end{array}$ \\
\hline Normal group & 75 & $\begin{array}{c}58 \\
(77.3)\end{array}$ & $\begin{array}{c}16 \\
(21.3)\end{array}$ & $\stackrel{1}{(1.3)}$ & \\
\hline Increased group & 22 & $\begin{array}{c}15 \\
(68.2)\end{array}$ & $\begin{array}{c}4 \\
(18.2)\end{array}$ & $\left(\begin{array}{c}2 \\
(9.1)\end{array}\right.$ & $\begin{array}{c}1 \\
(4.5)\end{array}$ \\
\hline Decreased group & 2 & 1 & 1 & & \\
\hline Total & 99 & 74 & 21 & 3 & 1 \\
\hline
\end{tabular}

\section{Histological findings of the pancreas}

Through microscopic examination of biopsy specimens of the pancreas, it was defined that those with histological changes should have proliferation of connective tissues and cell infiltration mainly composed of small round cells perceivable even with low magnification. The histological changes were further classified, depending on the grade, into those with mild changes (Fig. 1) and those with marked changes (Fig. 3). Of 151 patients with cholelithiasis, $23(15.2 \%)$ had mild changes and five $(3.3 \%)$ had marked changes, whereas, of 31 controls, $10(32.3 \%)$ and one $(3.2$ $\%$ ) had mild and marked changes, respectively. This means that it cannot be claimed that there is any statistically significant difference in the grade and frequency of histological change of the pancreas between the patients with cholelithiasis and the controls.

Relationship between the histological changes and the results of the secretin test: As indicated in Table 7 , in the group of patients with no or mild histological changes in the pancreas, $75-78 \%$ had normal results of the secretin test, whereas, of the five patients with marked histological changes, there was none who had normal results of the secretin test. In contrast, of the five who bad moderate or 


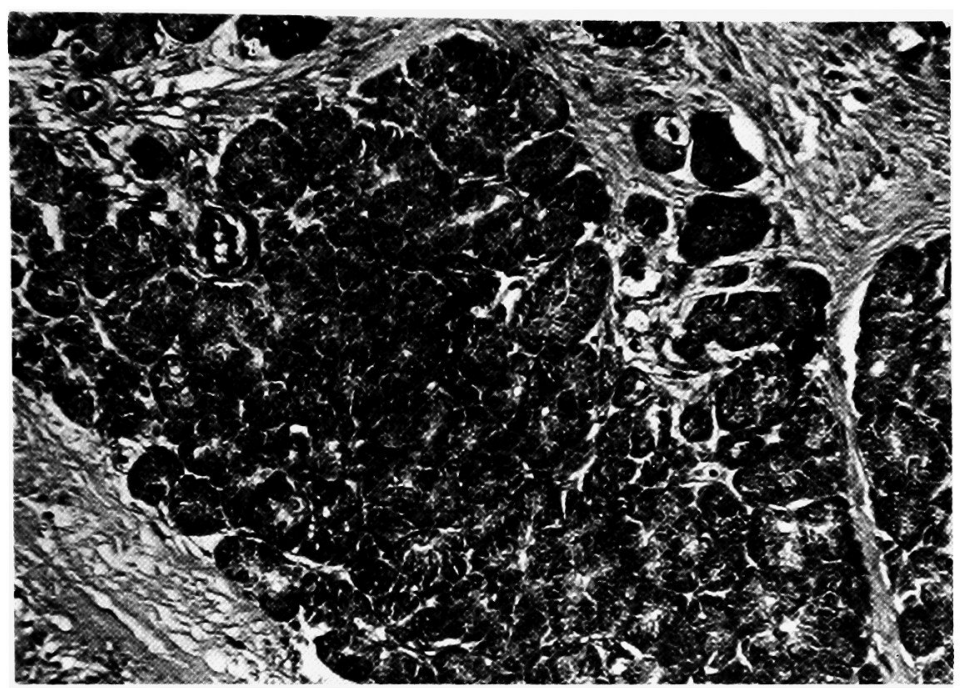

Fig. 1. Photomicrograph of the pancreas in patient (37-year-old male) with cholelithiasis, showing "mild change," depending on the grade of histological change. Hematoxylin and eosin, $25 \times 8$.

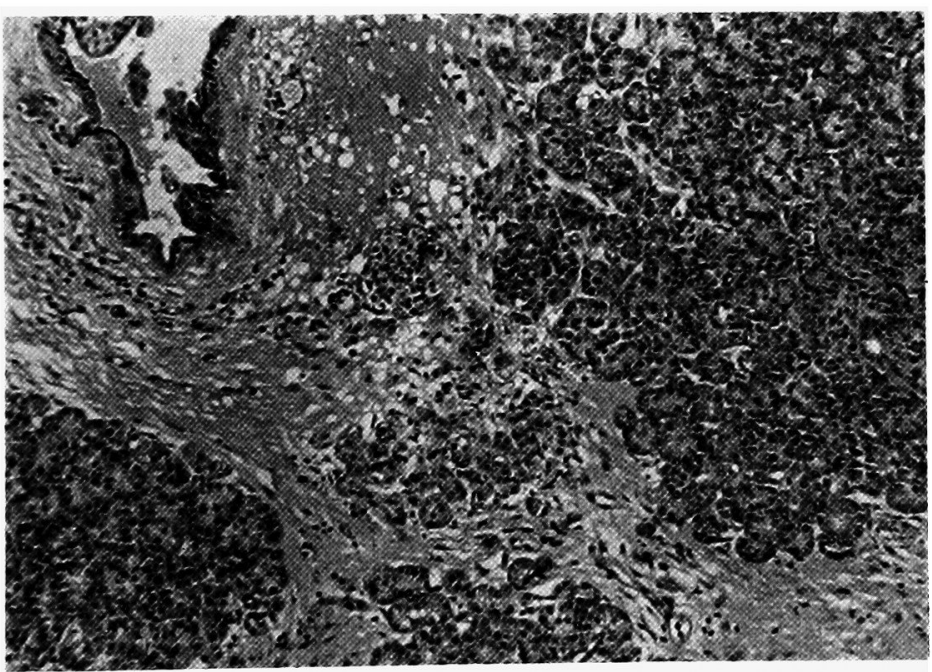

Fig. 2. Photomicrograph of the pancreas in patient (57-year-old male) with cholelithiasis, showing "moderate change." Hematoxylin and eosin, $10 \times 8$.

marked disturbance in the secretin test, one had negligible histological change in the pancreas and four had marked histological changes. Thus, the results were that the results of the secretin test correlate with the frequency and the grade of histological changes in the pancreas $(\mathrm{p}<0.01)$.

Relationship beween the location and type of gallstone and the histological change of the pancreas: Of all the 113 patients with stones in gallbladders, $92(81.4 \%)$ 


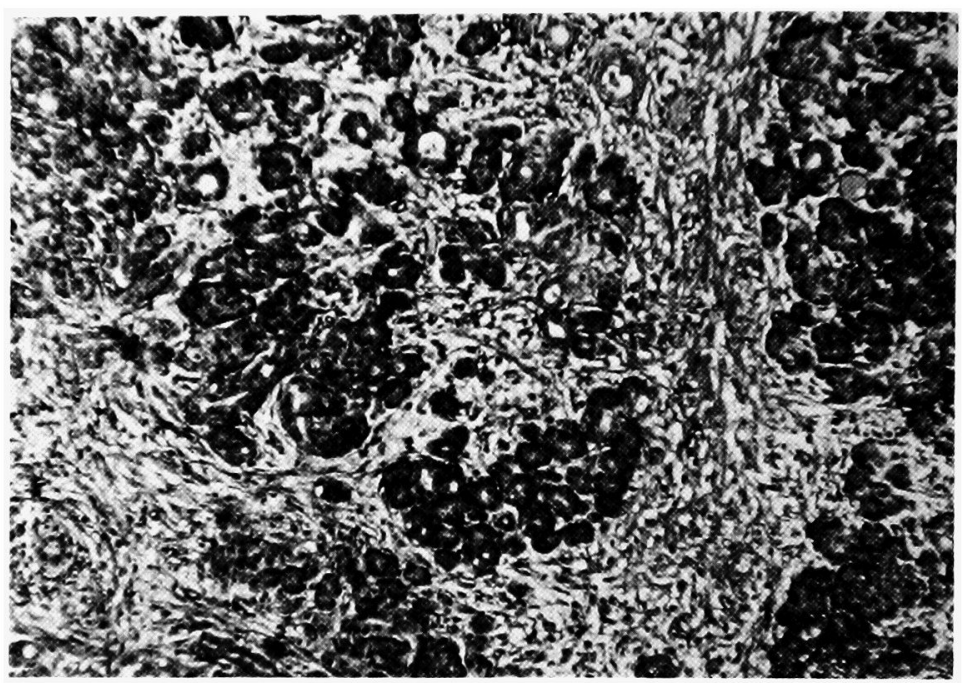

Fig. 3. Photomicrograph of the pancreas in patient (48-year-old female) with cholelithiasis, showing "marked change." Hematoxylin and eosin, $6 \times 8$.

TABLE 7. Relationship between histology of pancreas and results of secretin test

\begin{tabular}{|c|c|c|c|c|c|}
\hline \multirow[b]{2}{*}{ Histology of pancreas } & \multirow{2}{*}{$\begin{array}{l}\text { Number of } \\
\text { patients }\end{array}$} & \multicolumn{4}{|c|}{ Results of secretin test } \\
\hline & & Normal & Mild disturb. & $\begin{array}{l}\text { Moderate } \\
\text { disturb. }\end{array}$ & $\begin{array}{l}\text { Marked } \\
\text { disturb. }\end{array}$ \\
\hline No change & 98 & $\begin{array}{c}77 \\
(78.6)\end{array}$ & $\begin{array}{c}20 \\
(20.4)\end{array}$ & $\begin{array}{c}1 \\
(1.0)\end{array}$ & \\
\hline Mild change & 16 & $\begin{array}{c}12 \\
(75.0)\end{array}$ & $\begin{array}{c}4 \\
(25.0)\end{array}$ & & \\
\hline Marked change & 5 & & $\begin{array}{c}1 \\
(20.0)\end{array}$ & $\begin{array}{c}3 \\
(60.0)\end{array}$ & $\begin{array}{c}1 \\
(20.0)\end{array}$ \\
\hline Total & 119 & 89 & 25 & 4 & 1 \\
\hline
\end{tabular}

showed no histological change of the pancreas, whereas $18(15.2 \%)$ and three $(2.7 \%)$ had mild and marked histological changes, respectively. Of all the 24 patients who had stones in both gallbladder and bile duct, $19(79.2 \%)$ had no histological change of the pancreas, whereas four $(16.7 \%)$ and one $(4.2 \%)$ had mild and marked changes, respectively. Of all the 14 patients who had stones in bile duct, cases with no, mild and marked histological changes were $12(85.7 \%)$ and one each $(7.1$ $\%$ ), respectively (Table 8). Of all the 115 patients with cholesterol stones, 93 $(80.9 \%)$ showed no histological change of the pancreas, whereas $18(15.7 \%)$ and four $(3.5 \%)$ had mild and marked changes, respectively. Of all the 34 patients with calcium bilirubinate stones, $28(82.4 \%)$ showed no histological change of the pancreas, and five $(14.7 \%)$ and one $(2.9 \%)$ had mild and marked changes, respectively (Table 8). No significant difference was seen between the location and type of gallstone and the histological change of the pancreas. 
TABLE 8. Relationship between location of gallstone and histology of pancreas

\begin{tabular}{|c|c|c|c|c|}
\hline \multirow{2}{*}{ Location of stone } & \multirow{2}{*}{$\begin{array}{l}\text { Number of } \\
\text { patients }\end{array}$} & \multicolumn{3}{|c|}{ Histology of pancreas } \\
\hline & & No change & Mild change & $\begin{array}{l}\text { Marked } \\
\text { change }\end{array}$ \\
\hline Gallbladder & 113 & $\begin{array}{c}92 \\
(81.4)\end{array}$ & $\begin{array}{c}18 \\
(15.9)\end{array}$ & $\stackrel{3}{3}(2.7)$ \\
\hline $\begin{array}{l}\text { Gallbladder and bile } \\
\text { duct }\end{array}$ & 24 & $\begin{array}{c}19 \\
(79.2)\end{array}$ & $\begin{array}{c}4 \\
(16.7)\end{array}$ & $\begin{array}{c}1 \\
(4.2)\end{array}$ \\
\hline Bile duct & 14 & $\begin{array}{c}12 \\
(85.7)\end{array}$ & $(7.1)$ & $\left(7^{1} 1\right)$ \\
\hline Total & 151 & 123 & 23 & 5 \\
\hline
\end{tabular}

TABLE 9. Relationship between type of gallstone and histology of pancreas

\begin{tabular}{lcccc}
\hline & Number of & \multicolumn{3}{c}{ Histology of pancreas } \\
\cline { 5 - 5 } Type of stone & patients & No change & Mild change & $\begin{array}{c}\text { Marked } \\
\text { change }\end{array}$ \\
\hline Cholesterol stone & 115 & 93 & 18 & 4 \\
$\begin{array}{c}\text { Calcium } \\
\text { bilirubinate stone }\end{array}$ & 34 & $\begin{array}{c}(80.9) \\
(15.7)\end{array}$ & $(3.5)$ \\
Others & 2 & $(82.4)$ & $(14.7)$ & $(2.9)$ \\
\hline Total & 151 & 2 & & 5 \\
\hline
\end{tabular}

Relationship between the dilatation of bile duct and the histological change of the pancreas: Of 62 patients with dilated bile duct, $48(77.4 \%)$ had no histological change of the pancreas whereas $10(16.1 \%)$ and four $(6.5 \%)$ had mild and marked changes, respectively. Of 87 patients with non-dilated bile duct, $73(83.9 \%)$ showed no histological change of the pancreas, whereas $13(14.9 \%)$ and one $(1.1 \%)$ had mild and marked histological changes, respectively. (Table 10). Thus, the

TABLE 10. Relationship between dilatation of bile duct and histology of pancreas

\begin{tabular}{ccccc}
\hline & Number of & \multicolumn{3}{c}{ Histology of pancreas } \\
\cline { 3 - 5 } Bile duct & patients & No change & Mild change & $\begin{array}{c}\text { Marked } \\
\text { change }\end{array}$ \\
\hline Non-dilated group & 87 & 73 & 13 & 1 \\
Dilated group & 62 & $(83.9)$ & $(14.9)$ & $(1.2)$ \\
& & $(78.4)$ & $(16.1)$ & $(6.5)$ \\
\hline Total & 149 & 121 & 23 & 5 \\
\hline
\end{tabular}


cases with marked change in the pancreas were more frequent in the patients with dilated bile duct than those with non-dilated bile duct $(\mathrm{p}=0.17)$.

Relationship between the serum total cholesterol level and the histological change of the pancreas: As shown in Table 11, of all the 86 patients with the serum cholesterol content within normal range, $12(14.0 \%)$ showed mild histological change of the pancreas and one $(1.2 \%)$ had marked ones. Of all the 27 patients who had higher serum cholesterol content, three $(11.6 \%)$ each had mild and marked abnormalities. The patients who had marked change in the pancreas were more frequently observed among those who had higher serum cholesterol content $(p<$ $0.05)$.

TABLE 11. Relationship between total cholesterol content of serum and histology of pancreas

\begin{tabular}{ccccc}
\hline & & \multicolumn{3}{c}{ Histology of pancreas } \\
\cline { 3 - 5 } Content of cholesterol & $\begin{array}{c}\text { Number of } \\
\text { patients }\end{array}$ & No change & Mild change & $\begin{array}{c}\text { Marked } \\
\text { change }\end{array}$ \\
\hline Normal group & 86 & 73 & 12 & 1 \\
Increased group & 27 & $(84.9)$ & $(14.0)$ & $(1.2)$ \\
Decreased group & 2 & $(77.8)$ & $(11.1)$ & $(11.1)$ \\
Total & 115 & 2 & & 3 \\
\hline
\end{tabular}

Relationship between the results of culture of bacteria in bile and the histological change of the pancreas: Of all the 47 patients with positive results in the culture of bacteria in bile, $35(74.5 \%)$ showed no histological change of the pancreas, while nine $(19.1 \%$ ) and three $(6.4 \%)$ had mild and marked changes, respectively. Of all the 72 patients with negative results in the culture, $63(87.5 \%)$ showed no histological change of the pancreas, whereas seven $(9.7 \%)$ and two $(2.8 \%)$ had mild and marked changes, respectively. Thus, the group of patients with positive results in the culture of bacteria in bile tended to show higher frequency and severity of the change in the pancreas than the negative counterpart $(0.05<p<0.10)$ (Table 12).

TABLE 12. Relationship between result of culture of bacteria in bile and histology of pancreas

\begin{tabular}{ccccc}
\hline & Number of & \multicolumn{3}{c}{ Histology of pancreas } \\
\cline { 3 - 5 } Bacteria in bile & patients & No change & Mild change & $\begin{array}{c}\text { Marked } \\
\text { change }\end{array}$ \\
\hline Negative group & 72 & 63 & 7 & 2 \\
Positive group & 47 & $(87.5)$ & $(9.7)$ & $(2.8)$ \\
& & 35 & 9 & 3 \\
Total & 119 & 98 & $16.1)$ & $(6.4)$ \\
\hline
\end{tabular}


Relationship between duration of symptoms and the histological change of the pancreas: Of all the 63 patients with duration of symptoms for less than one year, $50(79.4 \%)$ showed no histological change of the pancreas, while $10(15.9 \%)$ and three $(4.8 \%)$ had mild and marked changes, respectively. Of all the 45 patients with duration of symptoms for one to five years, $34(75.6 \%)$ showed no histological change of the pancreas, while $10(22.2 \%)$ and one $(2.2 \%)$ had mild and marked changes, respectively. Further, of the 20 patients with duration of symptoms for five to 10 years, $19(95.0 \%)$ had no histological change of the pancreas, while only one $(5.0 \%)$ had mild change in the pancreas and there was none with marked change. Of the 17 patients with duration of symptoms for longer than 10 years, $15(88.2 \%)$ showed no histological change of the pancreas, while one each (5.9\% each) showed mild and marked changes (Table 13). Of the six patients who never complained of pains, five showed no histological change of the pancreas, while one showed mild change. Thus, there was no significant difference between the histological change of the pancreas and the duration of symptoms.

TABLE 13. Relationship between duration of symptoms and histology of pancreas

\begin{tabular}{ccccc}
\hline & & \multicolumn{3}{c}{ Histology of pancreas } \\
\cline { 3 - 5 } Duration of symptoms & $\begin{array}{c}\text { Number of } \\
\text { patients }\end{array}$ & No change & Mild change & $\begin{array}{c}\text { Marked } \\
\text { change }\end{array}$ \\
\hline - 1 year & 63 & 50 & 10 & 3 \\
$1-5$ years & 45 & $(79.4)$ & $(15.9)$ & $(4.8)$ \\
5-10 years & 20 & 34 & 10 & 1 \\
10 years - & 17 & $(75.6)$ & $(22.2)$ & $(2.2)$ \\
(Without pain) & 6 & 19 & 1 & \\
& & $(85.0)$ & $(5.0)$ & 1 \\
Total & 151 & $(83.3)$ & $(16.7)$ & $(5.9)$ \\
\hline
\end{tabular}

\section{Discussion}

In regard to the pancreatic exocrine function in cases, with cholelithiasis, many authors have reported considerable high frequency of the cases with disturbance of the function, even in Japan. However, present study indicated that the disturbance of pancreatic exocrine function was found to be present in only 30 cases $(25.2 \%)$ out of 119 patients examined. The results of our study showed lower frequency of the cases with disturbance of the pancreatic exocrine function than in the result so far reported (Miyake et al. 1960; Katsuki et al. 1973).

It is characteristic that the patients with cholelithiasis have mild disturbance in the pancreatic function, if examined with the secretin or pancreozymin-secretin test. In our 30 patients with disturbance of the pancreatic exocrine function, 25 
$(83.3 \%)$ showed mild disturbance. Thus, the higher frequency of disturbance defined by pancreatic exocrine function test in the patients with cholelithiasis can be attributed, as reported by Howat (1963), to that continuous flow of bile having lower concentration of bicarbonate into duodenum reduces the concentration of bicarbonate therein. In the results of our present study, too, $12(48 \%)$ out of 25 with mild disturbance in the pancreatic exocrine function showed decrease in the maximum bicarbonate concentration. As stressed by Dreiling (1955), the secretin or pancreozymin-secretin test can be justified as a diagnostic means for pancreatic diseases only when the function of biliary tract is normal. If the function of biliary tract is not normal as seen in the cases with cholelithiasis, the evaluation in this respect should be different. Particularly to be noted is that the drop in the maximum bicarbonate concentration as seen in the results of our present study is not attributed to disturbance of the pancreatic function, but may justifiably interpreted as derived from abnormalities in the bile duct system. The discrepancy between the results of study on the pancreatic exocrine function and those on the pancreatic histology in the cases with cholelithiasis may be justifiably realized through interpretations as mentioned above.

As for the histology of the pancreas in the cases with cholelithiasis, Takagi (1964) reported the result of study on 257 autopsy cases who died of various diseases that $36.5 \%$ thereof showed cellular infiltration, that $26.7 \%$ were of the group who had incomplete encapsulation of lobules, although increase in the interlobular connective tissues was observed, and that $24.5 \%$ were of the group who had increase in the intralobular connective tissues, but not accompanied by reconstruction of lobules. Further, Dierr (1953) reported, from the result of precise study on 130 autopsy cases with an average age of 52.4, that only 10 had completely normal pancreas, while the other 120 had more or less histological change in the pancreas. The latter group of his study had shown no symptom whatsoever which had implied any sign of pancreatitis during life. The histological pattern as he reported should not directly be identified as pancreatitis and it has yet to be solved how to interpret the histological change in the cases like these.

Sato (1958) reported, from the results of studies on 212 patients with upper abdominal diseases, that $57.3 \%$ showed more or less abnormalities such as atrophy of glandular cells, disappearance of zymogen granules, proliferation of interstitial connective tissues, infiltration of cells, hemorrhagia and congestion, and changes in pancreatic duct. However, he also stated that the frequency of abnormalities were reduced to $40.1 \%$ in terms of cell infiltration and proliferation of connective tissue. Of all the 31 patients with gastric cancer whom we used as the control group in our present study, $11(35.5 \%)$ showed the histological change in the pancreas, while, of all the 151 patients with cholelithiasis, $28(18.5 \%)$ showed the histological change.

Kojima and Sugamata (1970) suggested, in their report on the evaluation of 95 autopsy cases with chronic pancreatitis, that inflammatory change in any one location of specimens randomly collected should underline the confirmation thereof 
as pancreatitis. Thus, they proposed that those with fibrosis and cell infiltration perceivable even with minor magnification be called mild change (Fig. 1), that those as seen in Fig. 2 be called moderate change, and that those as seen in Fig. 3 be called marked change. The patients with moderate and marked changes showed clinical picture as well as function test almost proportionate to the changes. Therefore, we also examined the results of our present study in accordance with their evaluation standards. By his means, 23 were those with mild change as described above, while five were those with moderate or even marked change. The remaining 123 patients were judged as normal in accordance with their standards. The results of histological study correlate with the results of the secretin test. Furthermore, in patients with higher serum cholesterol values, many tended to indicate marked histological change of the pancreas, while, if viewed from the presence or absence of dilatation of bile duct, the group with dilated bile duct tended to show more frequent cases with marked histological change of the pancreas than the non-dilated group. When viewed also from the results of culture of bacteria in bile, the positive group and negative group tended to show some differences in the frequency of the cases with marked histological changes of the pancreas. However, no significant relationship could be seen between the location as well as the type of gallstones and the histological patterns. Thus, five $(3.3 \%)$ out of 151 cases with cholelithiasis who were evaluated in our study can be considered to be chronic pancreatitis.

The close relationship between pancreatitis and cholelithiasis has been accepted so far in view of many clinical facts. Molander and Bell (1946) reported that, of all the 160 autopsy cases with acute pancreatitis, those with gallstones were $36 \%$ in male and $68 \%$ in female. Lieber (1952) reported $41 \%$ thereon likewise and Newman et al. (1968) 54\%. As for clinical cases, Baker (1972), Trapnell (1972), Thal et al. (1957) and White (1966) reported thereon likewise 45-65\%, 54\%, 69\% and $74 \%$, respectively. In follow-up study of the patients with pancreatitis associated with cholelithiasis over one to seven years, Howard and Jordan (1960) reported recurrences in $53 \%$ out of 40 patients. Further, Trapnell (1966) reported that $59(72.0 \%)$ out of 82 patients for whom gallstones were not extirpated and three $(5.5 \%)$ out of 55 whose gallstones were extirpated showed recurrent attacks. On the relationship as above between pancreatitis and cholelithiasis, the following interpretations have so far been proposed: (1) the pathological changes encroach pancreatic head from bile duct via lymphatic tract (Weiner et al. 1970); (2) the pathological changes at the end of bile duct directly influence pancreatic head; or (3) bile duct and pancreatic duct may form a common tract.

Thus, pancreatitis is deemed to be in close relationship with cholelithiasis. However, from the standpoint of patients with cholelithiasis, the frequency of association of pancreatitis is not high; White (1966) reported that its frequency was approximately $5 \%$ of all the patients he examined. As for the frequency of association of acute pancreatitis in patients with cholelithiasis, Newman et al. (1968) stated in their report to be $0.9 \%$, while Dowdy (1969) $1.6 \%$. Miyake et al. 
(1960) reported it to be $1.1 \%$, while we claimed it to be $0.35 \%$ of all the 853 cases we examined. The frequency of association of chronic pancreatitis in patients with cholelithiasis has been reported by Sarles and Gerolami-Santandrea (1972) as $0.49 \%$, by Dowdy (1969) as $0.9 \%$, while, by Kozoll et al. (1959) as $1.5 \%$. In our present study, chronic pancreatitis was seen in $3.3 \%$ of 151 cases with cholelithiasis. It may have to be considered that the frequency of association of chronic pancreatitis in patients with cholelithiasis is unexpectedly low.

To summarize the results of our study, it was observed that there was a significant correlation between the results of the secretin test, the histology of the pancreas and the results of culture of bacteria in bile; the cases with moderate or marked disturbances in the secretin test and the cases with marked histological change of the pancreas tended to be frequently observed in those with dilated bile duct. However, there was no significant relationship between the duration of symptoms as well as location and type of gallstones, and the frequency as well as grade of pancreatic histological change and the results of the secretin test. In other words, it can be admitted relative to the relationship between cholelithiasis and pancreatitis that interpretations as described in (1), (2) and (3) are reasonable, but it was further deemed likely that there should be other factors which can not be explained with the above interpretations. As stated by Warren and Mountain (1971), that "cholelithiasis and pancreatitis have more common etiologic background than that the former is caused by the latter," it was deemed that there should be some common constitutional factors existing between cholelithiasis and chronic pancreatitis.

\section{References}

1) Baker, R.J. (1972) Acute surgical diseases of the pancreas. Surg. Clin. N. Amer., 52, 239-256.

2) Dierr, W. (1953) Fermententgleisung im Pankreas, pathologisch-anatomisch gesehen. Arztl. Wschr., 8, 681-690.

3) Dowdy, G.S., Jr. (1969) The Biliary Tract. Lea \& Febiger, Philadelphia, p. 289.

4) Dreiling, D.A. (1955) The technique of the secretin test. Normal ranges. J.Mt Sinai Hosp., 21, 363-372.

5) Hess, W. (1965) Surgery of the Biliary Passages and the Pancreas. D. van Nostrand Co. (Canada), Princeton, New Jersey, p. 90.

6) Howard, J.M. \& Jordan, G.L. (1960) Surgical Diseases of the Pancreas. J.B. Lippincott Co., Philadelphia and London, p. 92.

7) Howat, H.T. (1963) Chronisch rezidivierende Pankreatitis, II, Weltkongress für Gastroenterologie, 4, 3-60.

8) Katsuki, T., Nakashima, Y. \& Setoguchi, T. (1973) Gallstone pancreatitis: Its incidence entities and clinical significance. Acta med. Univ. Kagoshima, 15, Suppl., 169-184.

9) Kojima, K. \& Sugamata, H. (1970) Chronic pancreatitis viewed from pathology, Shinryo (Jap.), 23, 1471-1481.

10) Kozoll, D.D., Dwyer, G. \& Meyer, K.A. (1959) Pathologic correlation of gallstones -A review of 1,874 autopsies of patients with gallstones. Arch. Surg., 79, 514-536.

11) Lieber, M.M. (1952) The incidence of gallstones and their correlation with other diseases. Ann. Surg., 135, 394-405. 
12) Mallet-Guy, P. \& Beaujeu, M.J. (1950) Treatment of chronic pancreatitis by unilateral splanchnicectomy. Arch. Surg., 60, 233-241.

13) Miyake, H., Kuwatsuka, T. \& Sakai, M. (1960) Cholelithiasis and pancreatitis. Geka Chiryo (Jap.), 3, 355-368.

14) Molander, D.W. \& Bell, E.T. (1946) Relation of cholelithiasis to acute hemorrhagic pancreatitis. Arch. Path., 41, 17-18.

15) Newman, H.F., Northup, J.D., Rosenblum, M. \& Abrams, H. (1968) Complications of cholelithiasis. Amer. J. Gastroent., 50, 476-496.

16) Sarles, H. \& Gerolami-Santandrea, A. (1972) Chronic pancreatitis. Clinics in Gastroenterology, 1, (1), 167-193.

17) Sato, K. (1958) Histopathological study of pancreatitis associated with upper abdominal diseases. Tohoku Igaku Zassi (Jap.), 58, 354-366.

18) Takagi, T. (1964) Histopathologic study on the pancreas, with special reference to fibrosis on the exocrine portion. Juntendo med. J. (Jap.), 9, 146-170.

19) Thal, A.P., Perry, J.F., Jr. \& Egner, W. (1957) A clinical and morphologic study of forty-two cases of fatal acute pancreatitis. Surg. Gynec. Obstet., 105, 191-202.

20) Trapnell, J.E. (1966) The natural history and prognosis of acute pancreatitis. Ann. roy. Coll. Surg. Engl., 38, 265-287.

21) Trapnell, J. (1972) The natural history and management of acute pancreatitis. Clinics in Gastroenterology, 1, 147-166.

22) Warren, K.W. \& Mountain, J.C. (1971) Comprehensive management of chronic relapsing pancreatitis. Surg. Clin. N. Amer., 51, 693-710.

23) Weiner, S., Gramatica, L., Voegle, L.D., Hauman, R.L. \& Anderson, M.C. (1970) Role of the lymphatic system in the pathogenesis of inflammatory disease in the biliary tract and pancreas. Amer. J. Surg., 119, 55-61.

24) White, T.T. (1966) Pancreatitis, Edward Arnold, London, p. 8. 